\title{
Assessment of executive functions in obese individuals with binge eating disorder
}

\section{Avaliação de funções executivas em indivíduos obesos com transtorno da compulsão alimentar periódica}

\author{
Monica Duchesne, ${ }^{1,2}$ Paulo Mattos, ${ }^{1,3}$ José Carlos Appolinário, ${ }^{1,2}$ Silvia Regina de Freitas, ${ }^{1,2}$ Gabriel Coutinho, ${ }^{1,3}$ \\ Conceição Santos, ${ }^{2}$ Walmir Coutinho \\ ${ }^{1}$ Institute of Psychiatry, Universidade Federal do Rio de Janeiro (UFRJ), Rio de Janeiro, RJ, Brazil \\ 2 Obesity and Eating Disorders Group (GOTA), Instituto Estadual de Diabetes e Endocrinologia, Rio de Janeiro, RJ, Brazil \\ ${ }^{3}$ Centro de Neuropsicologia Aplicada, Rio de Janeiro, RJ, Brazil
}

\begin{abstract}
Objective: The aim of this study was to assess executive functions of obese individuals with binge eating disorder. Method: Thirty-eight obese individuals with binge eating disorder were compared to thirty-eight obese controls without binge eating disorder in terms of their executive functions. All individuals were assessed using the following instruments: Digit Span, Trail Making Tests A and B, Stroop Test and the Wisconsin Card Sorting Test. In addition, four subtests from the Behavioral Assessment of the Dysexecutive Syndrome Battery were also used, namely the Zoo Map Test, the Modified Six Elements Test, the Action Program Test and the Rule Shift Cards Test. Results: When compared to obese controls, obese individuals with binge eating disorder presented significant impairment in the following tests: Digit Span backward, Zoo Map Test, Modified Six Elements Test, and Action Program Test. Subjects with binge eating disorder also showed significant more set shifting and perseverative errors in the Wisconsin Card Sorting Test. In other measures such as the Digit Span Forward, the Trail Making Test, the Stroop Test and the Rule Shift Cards Test, obese subjects with binge eating disorder did not differ significantly from obese subjects without binge eating disorder. Conclusion: These results suggest that, in the present sample, obese individuals with binge eating disorder presented executive deficits, especially impairments relating to problem-solving, cognitive flexibility and working memory.
\end{abstract}

Descriptors: Binge eating disorder; Eating disorders; Obesity; Neuropsychology; Cognition

\section{Introduction}

Binge eating is a disturbed eating behavior regarded as a core feature of certain eating disorders such as bulimia nervosa (BN) and binge eating disorder (BED). Episodes of binge eating are

\section{Resumo}

Objetivo: $O$ objetivo desse estudo foi avaliar as funçōes executivas de individuos obesos com transtorno da compulsão alimentar periódica. Método: Trinta e oito indivíduos obesos com transtorno da compulsão alimentar periódica foram comparados com 38 controles obesos sem transtorno da compulsão alimentar periódica em termos de suas funçōes executivas. Todos os individuos foram avaliados utilizando os seguintes instrumentos: Digit Span, Trail Making Tests A $e$ B, Stroop Test $e$ Wisconsin Card Sorting Test. Adicionalmente, quatro subtestes da Behavioral Assessment of the Dysexecutive Syndrome Battery foram também utilizados, a saber: Zoo Map Test, Modified Six Elements Test, Action Program Test $e$ The Rule Shift Cards Test. Resultados: Quando comparados a controles obesos, indivíduos obesos com transtorno da compulsão alimentar periódica apresentaram déficits significativos no Digit Span Backward, Zoo Map Test, Modified Six Elements Test e no Action Program Test. Os indivíduos com transtorno da compulsão alimentar periódica também apresentaram significativamente mais erros perseverativos e de mudança de set no Wisconsin Card Sorting Test. Em outras medidas, tais como Digit Span Forward, Trail Making Test, Stroop Test $e$ The Rule Shift Cards Test, os individuos obesos com transtorno da compulsão alimentar periódica não diferiram significativamente dos obesos sem transtorno da compulsão alimentar periódica. Conclusão: Esses resultados sugerem que, neste estudo, os indivíduos obesos com transtorno da compulsão alimentar periódica apresentaram déficits executivos evidenciados por dificuldades na capacidade para resolução de problemas, na flexibilidade cognitiva e na memória operacional.

Descritores: Transtorno da compulsão alimentar; Transtornos alimentares; Obesidade; Neuropsicologia; Cognição

defined as a consumption of a large amount of food in a discrete period of time, accompanied by a subjective sense of loss of control over eating, as well as by marked distress. ${ }^{1}$ Individuals with BED 
present repeated binge eating episodes and feel guilty, disgusted, and depressed about their eating behaviors. ${ }^{1}$ However, unlike individuals with $\mathrm{BN}$, they do not engage in inappropriate weight control behaviors, and BED is frequently associated with obesity. ${ }^{1,2}$ As in other eating disorders, biological, psychological and social factors may play a role in the development and maintenance of BED. In terms of the psychological aspects involved, there are some evidences suggesting the contribution of a great variety of cognitive deficits in the physiopathology of eating disorders. ${ }^{3}$

Executive functions encompass a system of diverse cognitive skills which enable the individual to perform voluntary, autonomous, self-organized and target-oriented actions. They consist of a central administrative system, which is crucial not only for organizing and planning diverse cognitive processes, but also for integrating them in the long-term. Therefore, executive functions are involved in the ability to regulate impulsive behaviors ${ }^{4}$ For example, persons with cognitive impulsivity often find themselves in difficult situations because their decision making pattern is more influenced by immediate rewards then by future consequences (myopia to the future).$^{5-8}$ Besides mediating self-control, self-regulation and decision making in general, executive functions also play an important role in one's problem-solving capacity. ${ }^{4-8}$ As a result, executive deficits may impair the capacity for impulse regulation, including control over the impulse to eat excessively. ${ }^{9-11}$

A study with community-dwelling adults ${ }^{9}$ reported that increased dysexecutive traits were positively associated with disinhibited eating and greater food cravings. Other studies have linked binge eating episodes with an impaired capacity to control the impulse to overeat. ${ }^{10,11}$ In addition, neuropsychological testing research with $\mathrm{BN}$ patients have shown that they present executive deficits when compared to normal controls. ${ }^{3,12-15}$ Besides binge eating, individuals with eating disorders are also likely to engage in other maladaptive impulsive behaviors such as compulsive buying, thus suggesting a more pervasive behavioral impulse control problem. ${ }^{16-18}$ The existence of a high comorbidity between BED and attention-deficit hyperactivity disorder, which is associated with deficits in impulse control has also been reported. ${ }^{19}$

Obese individuals with BED often report great difficulty in controlling eating behaviors, despite a desire to lose weight. ${ }^{1}$ The sense of loss of control over eating reported by patients who binge eat, associated to neuropsychological data from patients with $\mathrm{BN}$ indicating low performance in executive functions tasks, suggest that executive deficits may play a role in the development and maintenance of binge eating. The purpose of the present study was to assess the executive functioning of obese individuals with BED using neuropsychological testing. Our hypothesis was that the performance of obese subjects with BED in executive function tests would be impaired when compared to obese individuals without BED.

\section{Method}

\section{Subjects}

Subjects were recruited from the Eating Disorders and Obesity Group outpatient clinic at the State Institute of Diabetes and
Endocrinology of Rio de Janeiro, Brazil. They were considered eligible for the study if they met the following inclusion criteria: (1) diagnosis of BED according to DSM-IV, (2) age between 18 and 45, (3) minimum of 6 years of schooling, (4) body mass index [BMI: weight $(\mathrm{kg}) /$ height $\left.^{2}\left(\mathrm{~m}^{2}\right)\right] \geq 30 \mathrm{~kg} / \mathrm{m}^{2}$, and (5) score in the Binge Eating Scale ${ }^{20}(\mathrm{BES})>17$ to include individuals with moderate and severe levels of binge eating.

From de 203 obese candidates initially assessed, 127 were excluded for the following reasons: history of brain injury or neurological diseases potentially associated with cognitive deficits, e.g. epilepsy (2\%); clinical diseases which could have an impact on their eating behavior or weight, e.g. diabetes and hypothyroidism (8\%); previous surgical treatment for obesity (1\%), psychotic disorder $(3 \%)$, history of bulimia nervosa or anorexia nervosa (9\%), presence of an eating disorder not otherwise specified (22\%), current major depressive disorder or bipolar depression, actual episode (23\%); use of medications which could influence either cognitive functioning or appetite $(13 \%)$, refusal to participate (2\%), and others $(7 \%)$.

The final study sample was comprised of 38 obese patients meeting DSM-IV criteria for BED and 38 obese subjects without BED. Patients had the following comorbidities: specific phobia $(12 \%)$, generalized anxiety disorder $(10 \%)$, dysthymic disorder $(6 \%)$, panic disorder (9\%), agoraphobia $(4 \%)$, social phobia (5\%), alcohol abuse/dependence $(3 \%)$, posttraumatic stress disorder $(3 \%)$, premenstrual dysphoric disorder $(2 \%)$, obsessivecompulsive disorder (2\%), and others (1\%).

\section{Procedures and measures}

In this cross-sectional study, patients underwent an assessment which included a psychiatric evaluation by a board-certified psychiatrist and a clinical evaluation by an endocrinologist. The presence of axis I disorders, including BED was assessed by means of the Portuguese language version of the Structured Clinical Interview for DSM-IV Axis I Disorders, Patient Version (SCID-I/P). ${ }^{21}$ Patients also completed the BES, ${ }^{20}$ which is a self-report scale that evaluates binge-eating severity. Weight and height of barefoot and lightly dressed subjects were measured on the day of testing utilizing a calibrated scale and a stadiometer. The set of neuropsychological tests employed was selected on the basis that they covered different aspects of executive functioning and were commonly used in clinical and research settings. The tests were administered individually to all subjects by a trained neuropsychologist using a standardized sequence.

Since global cognitive capacity differences between groups could jeopardize the subsequent comparison of executive functions, we used the Test of Nonverbal Intelligence- $3^{22}$ (TONI-3) to match both groups in terms of their general intellectual ability. TONI3 was chosen because it is language-free, non-motor and is not much influenced by culture. Patients were also matched by age, BMI and years of schooling. The following neuropsychological tests were administered:

1) The Digit Span, from the Wechsler Adult Intelligence ScaleIII. ${ }^{23}$ In this test, the subject is presented with a series of digits to 
be repeated in the same order (Digit Span forward) followed by another series to be repeated backwards (Digit Span backward). Digit Span foward assesses phonological loop and Digit Span backward assesses central executive aspects of the verbal working memory. The score was calculated based on the amount of numbers that could be immediately retained.

2) The Trail Making Test ${ }^{24}$ was used to assess psychomotor speed, visual integration, cognitive flexibility and inhibitory control. This test measures the subject's ability to connect written numbers in an ascending order (trail A), and, afterwards, to connect numbers and letters, alternating numbers in ascending order and letters in alphabetical order (trail B) like, for example, e.g. 1-A-2-B. The score was calculated according to the time spent to complete trail B.

3) The Stroop Test ${ }^{25}$ was used as a measure of seletive attention and inhibitory control. Subjects were given two trials. The color trial consists of reading a list of names of colors printed in colors different from those which they represent (e.g. the word blue is printed in gray). Next, in the color-word trial, the subject is presented with another list of words and asked to name the color of the ink in which the word is printed. In this test, which was adapted to Portuguese, the dependent variables were the number of right responses and the time needed to complete the task.

4) Behavioral Assessment of the Dysexecutive Syndrome: ${ }^{26} \mathrm{a}$ battery of tests designed to assess the presence of dysexecutive syndrome using tasks that simulate real life situations. Four subtests were administered:

a) The Zoo Map Test, which was designed to assess the subject's ability to formulate and implement a plan. Subjects are required to show how they would visit a series of designated locations on two drawn zoo maps without breaking a set of rules. In the first trial, the subject had to formulate the route (high-demand condition). In the second trial (low-demand condition), the patient is simply required to follow written instructions. The dependent variables were planning time, number of errors during the implementation of the plan and time required to complete task.

b) The Action Program Test, which involves novel problem solving. This test was designed to assess the subjects' ability to devise a plan of action and implement a solution to a practical problem, in this case, getting a cork out of a narrow tall plastic tube, a result which can only be achieved by the planned use of various other materials provided. Five stages are needed to solve the problem properly and the score is calculated according to the number of stages completed.

c) The Modified Six Elements Test, which was designed to measure planning, task scheduling and performance monitoring. It involves the subject managing the time available to perform three simple tasks (naming a set of pictures, arithmetic calculations and a dictation), each of which divided into two parts. There was one rule that could not be broken: they were not allowed to do the two parts of the same task consecutively. The dependent variable was based on the number of tasks completed minus the number of tasks where a rule was broken (i.e. doing part $\mathrm{A}$ and $\mathrm{B}$ of the same task consecutively). d) The Rule Shift Cards Test, which measures perseverative tendencies and cognitive flexibility. It requires subjects to respond correctly to stimuli (red or black playing cards) according to one of the two rules that are consecutively presented to them. Performance is scored depending on how successfully the respondent shifts from applying the first rule to applying the second rule. The variables used were the number of errors made and completion time.

5) The Wisconsin Card Sorting Test ${ }^{27}$ (WCST) measures categorization, inference, testing of hypotheses, cognitive flexibility, cognitive inhibition, and response to feedback. In this test, subjects are instructed to categorizate a series of cards according to one of the three stimulus features (color, shape or number of illustrations on them), without this principle being revealed to the subject. After each association, the only feedback given is whether a match is correct or incorrect, the idea being that subjects should infer how to categorize based on the feedback they received. The number of total errors, perseverative errors and failure to maintain set were the dependent measures.

This research was reviewed and approved by the institutional review board of the hospital and a written informed consent was obtained from all subjects prior to participation.

\section{Statistical analysis}

The Kolmogorov-Smirnov test was used to assess if data had a normal distribution. The Mann-Whitney Test ${ }^{28}$ was used to ascertain whether there weren't statistically significant differences between those subjects diagnosed with BED and those who weren't in terms of age, BMI, years of schooling, BES and TONI-3 scores. Quantitative variables were described as means and standard deviations, while categorical variables were described using frequency and percentages. Neuropsychological test results were analyzed considering raw scores and/or time to complete the task, namely in seconds. The Mann-Whitney Test was used to determine statistically significant differences in the neuropsychological tests scores across groups. A logistic regression ${ }^{29}$ was then applied to determine if gender had a significant influence in the neuropsychological assessment results. The dependent variable used in the regression was the diagnosis of BED and the independent variables were gender and all subtests with significant results. The Statistical Package for the Social Sciences (SPSS), version 13.0 was used to analyze data. All statistical tests were interpreted at the $5 \%$ significance level.

\section{Results}

The mean age of the overall sample was 34.96 years $(S D=6.66)$, with a mean $\mathrm{BMI}$ of $36.24(\mathrm{SD}=3.35)$ and a mean education level of 11.83 years of schooling $(\mathrm{SD}=2.43)$. Additionally, most of the subjects were female (82.9\%) of which $38.2 \%$ belonged to the BED group and $44.7 \%$ to the obese control group.

The BED and non-BED obese subjects were well matched in respect to age, BMI, years of schooling, and level of intelligence as measured by the TONI-3. The mean BES score was significantly higher in the obese patients with BED, as compared to the obese 
Table 1 - Means and standard deviations of the clinical and demographic characteristics among subjects with binge eating disorder and obese controls

\begin{tabular}{lccc}
\hline Characteristics & $\begin{array}{c}\text { Obese with } \\
\text { BED } \\
\mathbf{N}=\mathbf{3 8}\end{array}$ & $\begin{array}{c}\text { Obese } \\
\text { controls } \\
\mathbf{N}=\mathbf{3 8}\end{array}$ & $\begin{array}{c}\text { Mann- } \\
\text { Whitney } \\
\mathbf{p}\end{array}$ \\
\hline Age (years) & $33.29(5.01)$ & $35.42(7.88)$ & 0.93 \\
BMI $\left(\mathrm{kg} / \mathrm{m}^{2}\right)$ & $35.89(2.91)$ & $36.60(3.75)$ & 0.73 \\
Years of schooling & $11.66(2.46)$ & $12.82(2.36)$ & 0.77 \\
Binge Eating Scale & $28.53(5.67)$ & $6.37(4.43)$ & $0.00^{\star}$ \\
TONI-3 & $23.45(4.23)$ & $23.32(4.05)$ & 0.89 \\
\hline
\end{tabular}

$B E D=$ binge eating disorder, $N=$ number; $B M I=$ Body Mass Index; TONI-3 = Test of Nonverbal Intelligence-3

*Significant. Test statistics: Mann-Whitney Test $(p \leq 0.05)$.

without BED. Clinical and demographic characteristics of the two groups are summarized in Table 1, along with the statistical test results.

Relative to the obese control individuals, BED subjects were significantly impaired in Digit Span Backward, but not in Digit Span Forward. In addition, no significant differences between obese with BED and those without BED was found in trails A and $\mathrm{B}$ of the Trail Making Test, as well as in any measure regarding the Color-Word trial of the Stroop Test. Moreover, in the Rule
Shift Cards, the number of rule shift errors and the time needed to complete tasks were similar. Data on the groups' performance in all neuropsychological tests are presented in Table 2.

As compared to the obese controls, BED subjects showed a higher number of errors in trial 1 of the Zoo Map Test, but no significant differences were observed in both planning and completion times. Additionally, in trial 2, the performance of the two groups was not significantly different in terms of the number of errors and in planning and completion times. In the Modified Six Elements Test, obese individuals without BED scored significantly worse compared to obese subjects with BED. Regarding the Action Program Test, BED subjects completed fewer stages than obese individuals without BED. The WCST revealed that BED subjects made significantly more perseverative and set-shifting errors than obese individuals without BED. Nonetheless, the two groups did not present significant differences with regards to the total number of errors (Table 2). An analysis using logistic regression indicated that gender had a significant influence on $\mathrm{BED}(\mathrm{OR}=57 ; \mathrm{p}=0.07)$. After adjustment for gender, all the significant neuropsychological measures did not show materially important changes and all variables remained statistically significant (Table 3).

Table 2 - Means and standard deviations of raw scores and completion time of the neuropsychological tests

\begin{tabular}{|c|c|c|c|}
\hline Neuropsychological tests & $\begin{array}{c}\text { Obese with BED } \\
\qquad N=38\end{array}$ & $\begin{array}{l}\text { Obese controls } \\
\qquad \mathrm{N}=38\end{array}$ & $\begin{array}{c}\text { Mann-Whitney } \\
\text { p }\end{array}$ \\
\hline \multicolumn{4}{|l|}{ Action Program Test (BADS) } \\
\hline Number of stages completed & $3.89(1.11)$ & $4.47(0.76)$ & $0.01^{\star \star}$ \\
\hline \multicolumn{4}{|l|}{ Rule Shift Cards (BADS) } \\
\hline Number of errors & $3.89(2.99)$ & $2.74(2.63)$ & 0.07 \\
\hline Completion time & $40.21(10.06)^{\star}$ & $38.05(7.28)^{\star}$ & 0.47 \\
\hline \multicolumn{4}{|l|}{ Zoo Map Test (BADS) } \\
\hline Trial 1: Number of errors & $2.55(1.44)$ & $1.79(0.96)$ & $0.01^{\star \star}$ \\
\hline Trial 1: Planning time & $40.34(42.07)^{\star}$ & $26.87(18.7)^{\star}$ & 0.16 \\
\hline Trial 1: Completion time & $210.29(94.48)^{\star}$ & $208.61(83.11)^{\star}$ & 0.19 \\
\hline Trial 2: Number of errors & $0.84(0.94)$ & $0.50(0.64)$ & 0.14 \\
\hline Trial 2: Planning time & $5.58(6.78)^{\star}$ & $6.37(4.58)^{\star}$ & 0.11 \\
\hline Trial 2: Completion time & $98.01(50.45)^{\star}$ & $103.50(47.05)^{\star}$ & 0.33 \\
\hline Modified Six Elements (BADS) ${ }^{\star \star \star}$ & $4.08(1.42)$ & $4.74(1.32)$ & $0.04^{\star \star}$ \\
\hline \multicolumn{4}{|l|}{ WCST } \\
\hline Total errors & $45.6(9.70)$ & $43.1(5.70)$ & 0.12 \\
\hline Perseverative errors & $18.42(9.69)$ & $12.87(8.64)$ & $0.02^{\star \star}$ \\
\hline Failure to maintain set & $2.15(1.31)$ & $1.25(0.75)$ & $0.03^{\star \star}$ \\
\hline Trail Making Test (trial B) & $94.05(37.63)^{\star}$ & $81.34(33.53)^{\star}$ & 0.06 \\
\hline \multicolumn{4}{|l|}{ Stroop Test } \\
\hline Color-Word trial: Correct answers & $94.71(14.07)$ & $95.18(9.01)$ & 0.69 \\
\hline Color-Word trial: Completion time & $122.95(2.74)^{\star}$ & $120.63(7.94)^{\star}$ & 0.56 \\
\hline \multicolumn{4}{|l|}{ Digit Span } \\
\hline Forward: correct responses & $6.32(1.78)$ & $6.82(1.18)$ & 0.54 \\
\hline Backward: correct responses & $4.29(1.95)$ & $5.13(1.37)$ & $0.02^{\star \star}$ \\
\hline
\end{tabular}

$B E D=$ binge eating disorder; $B A D S=$ Behavioral Assessment of the Dysexecutive Syndrome

* Completion time in seconds; ** Significant. Test statistics: Mann-Whitney Test ( $p \leq .05) ; * \star *$ Tasks completed minus tasks with rule break; WCST $=$ Wisconsin Card Sorting Test. 
Table 3 - Odds ratio* (OR) for neuropsychological tests for binge eating disorder $(\mathrm{N}=76)$

\begin{tabular}{lcc}
\hline \multicolumn{1}{c}{ Neuropsychological tests } & OR & p-value \\
\hline Action Program Test & & \\
Number of stages completed & 3.60 & 0.02 \\
Zoo Map Test & & \\
Trial 1: Number of errors & 0.26 & 0.03 \\
Modified Six Elements & 0.39 & 0.02 \\
Wisconsin Card Sorting Test & & \\
Perseverative errors & 0.87 & 0.01 \\
Failure to maintain set & 0.32 & 0.01 \\
Digit Span & & \\
Backward: Correct responses & 2.30 & 0.02 \\
\hline
\end{tabular}

* Adjusted for gender

\section{Discussion}

To the best of our knowledge, the current study is the first exploratory investigation of executive functions as performed by obese individuals with BED using neuropsychological tests to assess working memory, cognitive flexibility, inhibitory control, categorization, testing of hypotheses, planning, problem-solving ability, task scheduling, and performance monitoring. Altogether, out of the eight neuropsychological tests applied, the performance of individuals with BED differed significantly from that of obese without BED on five such tests.

Set shifting involves shifting back and forth between multiple tasks, operations, or mental sets. ${ }^{4,30}$ Deficits shown by BED subjects in both the WCST and the Modified Six Elements Test suggest an impairment in their ability to shift attention and behavior from one set to another. A common complaint by patients with BED is that they find it difficult to stop thinking about food, even when they try to distract themselves. Binge eating seems to be associated to multidetermined factors, ${ }^{31}$ and it's tempting to suggest that set shifting deficits might have some relation to the BED patients' reported difficulty to shift their attention from a food signal (e.g., a chocolate bar or food-related thoughts) to other activities. This impairment in their ability to shift their behavior might also be partly associated to their reported difficulty in stopping a binge eating episode once it starts, thus causing BED individuals to stop eating only when they feel physically uncomfortable.

BED subjects performed poorly in the first trial of the Zoo Map Test and in the Action Program Test. These results suggest that the planning and problem-solution abilities of the obese with BED are impaired. In normal everyday activities, obese individuals with BED may face a variety of situations in which they are subjected to a great deal of exposure to food-related stimuli and, in certain social occasions, even to pressure to eat. Their difficulty in being able to plan ahead how to manage circumstances and to devise solutions to deal with different problematic scenarios may be a facilitator of binge eating episodes. In addition, their impaired mental flexibility may also be associated with a difficulty in establishing new patterns of behavior regarding food-related activities, thus contributing to binge-eating episodes.
BED subjects presented a worse performance in the Digit Span backward, a task that has been previously demonstrated to be a reliable measure of working memory. ${ }^{32}$ Briefly, working memory refers to the ability of temporarily maintaining and manipulating relevant information one needs to keep in mind. Working memory resources seem to be critical for good emotional decision-making since they appear to be involved in the continuous proper appraising of all relevant aspects necessary to making overall good decisions. ${ }^{33}$ Studies focused on decision-making tasks have shown that, when an excessive load was placed on a subject's working memory, he or she found it difficult to fully integrate relevant information, thus leading him or her to make choices based solely on the immediate rewards as opposed to the overall information he or she had accumulated from past experiences. ${ }^{7,8,33}$ Previous studies ${ }^{34,35}$ with obese individuals reported that their decisionmaking ability proved to be poor (as assessed by a validated computerized gambling task) because they chose to behave according to immediate rewards even if faced with future longterm negative consequences. It has been suggested that overeating is not simply a passive response to salient environmental triggers and powerful physiological drives. It is also related to the inability both to forego short-term rewards in face of deleterious long-term consequences and to making choices based on the assessment of future advantageous consequences when various options for action are available.

It is tempting to infer that patients with BED may engage in binge eating episodes, which is a hallmark of their disorder partly due to a deficit in working memory, which impairs their capacity to keep track of an ongoing impulsive act, i.e., the binge. The difficulty they experience in self-inhibiting their food consumption may be partially related to an attentional focus on the immediate pleasures associated with eating, accompanied by an apparent inability to both consider past negative outcomes associated with their eating behavior (e.g., guilt, sadness, undesired weight gain) and to choose a more rewarding outcome ("If I control myself now, I will not gain weight). The employment of a more extensive battery of tasks to measure the various aspects of the subjects' working memory, as well as tasks to evaluate their decision-making ability could help clarify possible related deficits.

The findings in the current study could help explain, at least partially, some of the good results achieved with the employment of cognitive-behavioral therapy techniques for use in obese individuals with BED. ${ }^{36,37}$ For example, it can be speculated that self-monitoring (registering in writing all food eaten), a frequently employed strategy in cognitive-behavioral therapy may be associated with an increase in a patient's attention to what he or she is eating, which, in turn, may decrease the load placed on the subject's working memory. Another set of cognitive-behavioral therapy techniques would be the stimulus-control techniques, which involve narrowing the spectrum of stimulating situations that may induce binge eating episodes. These strategies could help patients deal with their difficulties in set shifting by providing a "safer" environment where fewer triggering situations are found. 
In the present study, BED subjects had a normal performance in the second trial of the Zoo Map test, a low-demand task in which the subject has to follow a previously formulated plan. However, their performance on the first trail, which requires subjects to display a spontaneous planning ability with little help, was below par.

These results have certain implications on psychotherapy. Even though BED patients in general respond well to various psychotherapy interventions, they occasionally relapse into binge eating. ${ }^{37}$ During psychotherapy, BED patients are usually counseled on how to deal with challenging scenarios, however, once therapy is over, they need to take onto themselves the responsibility for developing and implementing solutions to these challenging scenarios. The possible consequences of our findings in terms of treatment include the need to give more emphasis to developing the patients' problem-solving abilities, which would make them better equipped to deal with binge-related challenges, thus helping to prevent relapse.

The Rule Shift Cards Test, the Trail Making Test and the Stroop Test, which measure cognitive flexibility and inhibitory control, did not detect any impairment in obese subjects with BED, although the Rule Shift Cards Test and the Trail Making Test nearly reached significance. Our results suggest that differences in impairment levels may differ according to the type of task used in testing, The WCST was where the BED group in our study revealed to be the most impaired. Although eating disorders seem to be associated with a certain degree of neuropsychological dysfunction, conclusions regarding the specific functions which are impaired, as well as the degrees of impairment of cognitive functions in different tasks are not consistent among studies. ${ }^{3}$ The fact that our sample was a small sample and that larger samples of obese individuals with and without BED could show subtle differences should also be taken into consideration. Another explanation for some of the negative findings is that certain neuropsychological tests used in this study were developed based on brain injury studies, and it seems reasonable to consider that some of the tasks were not sensitive enough to detect subtle deficits that are possibly present in individuals from our sample.

A further limitation of the present study is the lack of a normalweight control group. Recent results from two studies conducted with morbidly obese individuals who were candidates for weightloss surgery suggested a link between obesity and deficits in executive functioning, namely planning, problem solving and mental flexibility in comparison to normative data. ${ }^{38,39}$ Even though evidence regarding deficits in executive functioning in obese individuals is still scarce, one may infer that the lack of significant differences between the BED and the non-BED obese subjects observed in some of the tests employed in our study could be due to the possibility that, in general, obese individuals present executive deficits.

\section{Conclusion}

Obese subjects with BED presented deficits in problem solving, cognitive flexibility and working memory, which may all be related to binge-eating episodes. Further studies with larger sample sizes and with carefully matched obese and normal-weight controls are required to evaluate the potential role of executive deficits in the development and maintenance of binge eating episodes in obese individuals with BED. Such studies could broaden the current investigation and make new contributions to the theoretical knowledge relating to BED. 


\section{Disclosures}

\begin{tabular}{|c|c|c|c|c|c|c|c|}
\hline $\begin{array}{l}\text { Writing group } \\
\text { member }\end{array}$ & Employment & $\begin{array}{l}\text { Research } \\
\text { grant }^{1}\end{array}$ & $\begin{array}{c}\text { Other research grant } \\
\text { or medical continuous } \\
\text { education }^{2}\end{array}$ & $\begin{array}{l}\text { Speaker's } \\
\text { honoraria }\end{array}$ & $\begin{array}{l}\text { Ownership } \\
\text { interest }\end{array}$ & $\begin{array}{l}\text { Consultant/ } \\
\text { Advisory board }\end{array}$ & Other $^{3}$ \\
\hline $\begin{array}{l}\text { Monica } \\
\text { Duchesne }\end{array}$ & IEDE & - & - & - & - & - & - \\
\hline Paulo Mattos & UFRJ & $\begin{array}{l}\text { Janssen- } \\
\text { Cilag }^{*}\end{array}$ & Janssen-Cilag* & $\begin{array}{l}\text { Janssen- } \\
\text { Cilag* }^{*} \\
\text { Novartis*}^{*}\end{array}$ & - & $\begin{array}{c}\text { Janssen-Cilag* } \\
\text { Novartis }^{\star}\end{array}$ & - \\
\hline $\begin{array}{l}\text { José Carlos } \\
\text { Appolinário }\end{array}$ & Janssen-Cilag* & - & - & - & - & - & - \\
\hline $\begin{array}{l}\text { Silvia Regina de } \\
\text { Freitas }\end{array}$ & IEDE & - & - & - & - & - & - \\
\hline $\begin{array}{l}\text { Gabriel } \\
\text { Coutinho }\end{array}$ & CNA & - & - & - & - & - & - \\
\hline $\begin{array}{l}\text { Conceição } \\
\text { Santos }\end{array}$ & IEDE & - & - & - & - & - & - \\
\hline $\begin{array}{l}\text { Walmir } \\
\text { Coutinho }\end{array}$ & IEDE & $\begin{array}{l}\text { Abbott* } \\
\text { Roche* } \\
\text { Merck* } \\
\text { Janssen- } \\
\text { Cilag }^{\star}\end{array}$ & - & $\begin{array}{c}\text { Sanofi- } \\
\text { Aventis* } \\
\text { Abbott* }^{*} \\
\text { Roche }^{\star} \\
\text { Novartis* } \\
\text { Aché }^{\star}\end{array}$ & - & $\begin{array}{c}\text { Abbott* } \\
\text { Roche }^{\star} \\
\text { Medley }^{\star} \\
\text { Merck }^{\star} \\
\text { Janssen-Cilag* }\end{array}$ & - \\
\hline
\end{tabular}

*Modest

** Significant

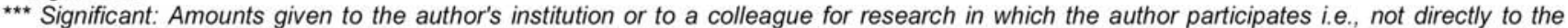
author.

Note: IEDE = Instituto Estadual de Diabetes e Endocrinologia; UFRJ = Universidade Federal do Rio de Janeiro; CNA = Centro de Neuropsicologia Aplicada.

For more information, see Instructions for Authors.

\section{References}

1. American Psychiatric Association - APA. Diagnostic and statistical manual of mental disorders. 4th ed. Washington (DC): American Psychiatric Press; 2000.

2. Spitzer RL, Yanovski S, Wadden T, Wing R, Marcus MD, Stunkard A, Devlin M, Mitchell J, Hasin D, Horne RL. Binge eating disorder: its further validation in a multisite study. Int J Eat Disord. 1993;13(2):137-53.

3. Duchesne M, Mattos P, Fontenelle LF, Veiga H, Rizo L, Appolinario JC. Neuropsychology of eating disorders: a systematic review of the literature. Rev Bras Psiquiatr. 2004;26(2):107-17.

4. Lezak MD. Executive functions and motor performance. In: Lezak MD, editor. Neuropsychological assessment. 2nd ed. New York: Oxford University Press; 2004. p.611-41

5. Bechara A, Damasio H. Decision-making and addiction (part II): myopia for the future or hypersensitivity to reward? Neuropsychologia. 2002;40(10):1690-705.

6. Malloy-Diniz L, Fuentes D, Borges LW, Correa H, Bechara A. Impulsive behavior in adults with attention deficit/hyperactivity disorder: Characterization of attentional, motor and cognitive impulsiveness. $J$ Int Neuropsychol Soc. 2007;13(4):693-8.

7. Hinson J, Jameson T, Whitney P. Somatic markers, working memory, and decision making. Cogn Affect Behav Neurosc. 2002;2(4):341-53.

8. Hinson J, Jameson T, Whitney P. Impulsive decision making and working memory. J Exp Psychol Learn Mem Cogn. 2003;29(2):298-306.

9. Spinella M, Lyke J. Executive personality traits and eating behavior. Int J Neurosci. 2004;114(1):83-93.

10. Steiger H, Lehoux PM, Gauvin L. Impulsivity, dietary control and the urge to binge in bulimic syndromes. Int J Eat Disord. 1999;26(3):261-74.

11. de Zwaan M, Mitchell JE, Seim HC, Specker SM, Pyle RL, Raymond NC, Crosby RB. Eating related and general psychopathology in obese females with binge eating disorder. Int J Eat Disord. 1994;15(1):43-52.

12. Tchanturia K, Anderluh MB, Morris RG, Rabe-Hesketh S, Collier DA, Sanchez P, Treasure JL. Cognitive flexibility in anorexia nervosa and bulimia nervosa. J Int Neuropsychol Soc. 2004;10(4):513-20.
13. Lauer CJ, Gorzewski B, GerlinghoffM, Backmund H, Zihl J. Neuropsychological assessments before and after treatment in patients with anorexia nervosa and bulimia nervosa. J Psychiatr Res. 1999;33(2):129-38.

14. Jones BP, Duncan CC, Brouwers P, Mirsky AF. Cognition in eating disorders. J Clin Exp Neuropsychol. 1991;13(5):711-28.

15. Kaye WH, Bastiani AM, Moss H. Cognitive style of patients with anorexia nervosa and bulimia nervosa. Int J Eat Disord. 1995;18(3):287-90.

16. Fernández-Aranda F, Pinheiro AP, Thornton LM, Berrettini WH, Crow S, Fichter MM, Halmi KA, Kaplan AS, Keel P, Mitchell J, Rotondo A, Strober M, Woodside DB, Kaye WH, Bulik CM. Impulse control disorders in women with eating disorders. Psychiatry Res. 2008; 157(1):147-57.

17. McElroy SL, Keck PE, Phillips KA. Kleptomania, compulsive buying, and binge-eating disorder. J Clin Psychiatry. 1995;56(Suppl 4):14-26.

18. Faber RJ, Christenson GA, de Zwaan M, Mitchell J. Two forms of compulsive consumption: Comorbidity of compulsive buying and binge eating. $J$ Consum Res. 1995;22(3):296-304.

19. Mattos P, Saboya E, Ayrāo V, Segenreich D, Duchesne M, Coutinho G. Comorbid eating disorders in a Brazilian attention deficit/hyperactivity disorder adult clinical sample. Rev Bras Psiquiatr. 2004;26(4):248-50.

20. Freitas S, Lopes CS, Coutinho W, Appolinario JC. Translation and adaptation into portuguese of the Binge-Eating Scale. Rev Bras Psiquiatr. 2001;23(4):215-20

21. First MB, Spitzer RL, Gibbon M, Williams JBW. The structured clinical interview for DSM-IV Axis I disorders - patient edition (SCID-I/P, Version 2.0). New York: Biometrics Research Department, State Psychiatric Institute; 1995.

22. Brown L, Sherbenou RJ, Johnsen SK. Test of Nonverbal Intelligence-3 (TONI-3). Odessa: Psychological Assessment Resources Inc.; 1997.

23. Wechsler D. Wechsler adult intelligence scale-III - administration and scoring manual. San Antonio: Psychological Corporation; 1997.

24. Reitan RM, Wolfson D. The Halstead-Reitan neuropsychological test battery: Theory and clinical interpretation. Tucson: Neuropsychology Press; 1985. 
25. Trenerry MR, Crosson B, DeBoe J, Leber WR. The stroop neuropsychological screening test. Odessa: Psychological Assessment Resources; 1989.

26. Wilson BA, Alderman N, Burgess PW, Emslie H, Evans JJ. Behavioral assessment of the dysexecutive syndrome. Oxford: Thames Valley Test Company; 1996.

27. Heaton RK. Wisconsin card sorting test: Computer Version. Odessa: Psychological Assessment Resources Inc.; 2000.

28. Siegel S, Castellan J. Nonparametric statistics for the behavioral sciences. 2nd ed. New York: McGraw-Hill; 1988.

29. Hosmer DW, Lemeshow S. Applied logistic regression. New York: WileyInterscience Press; 1989.

30. Miyake A, Friedman NP, Emerson MJ, Witzky AH, Howerther A, Wager TD. The unity and diversity of executive function and their contribution to complex "frontal lobe" tasks: a latent variable analysis. Cogn Psychol. 2000;41(1):49-100.

31. Stein RI, Kenardy J, Wiseman CV, Dounchis JZ, Arnow BA, Wilfley DE. What's driving the binge in binge eating disorder? A prospective examination of precursors and consequences. Int J Eat Disord. 2007;40(3):195-203.

32. Baddeley AD. Recent developments in working memory. Curr Opin Neurobiol. 1998;8(2):234-8.

33. Dretsch MN, Tipples J. Working memory involved in predicting future outcomes based on past experiences. Brain Cogn. 2008;66(1):83-90.

34. Davis C, Levitan RD, Muglia P, Bewell C, Kennedy JL. Decision-making deficits and overeating: a risk model for obesity. Obes Res. 2004;12(6):929-35

35. Pignatti R, Bertella L, Albani G, Mauro A, Molinari E, Semenza C. Decisionmaking in obesity: a study using the Gambling Task. Eat Weight Disord. 2006;11(3):126-32.

36. Duchesne M, Appolinario JC, Rangé BP, Fandiño J, Moya T, Freitas SR. The use of a manual-driven group cognitive behavior therapy in a Brazilian sample of obese individuals with binge-eating disorder. Rev Bras Psiquiatr. 2007;29(1):23-5.

37. American Psychiatric Association - APA. Practice guideline for the treatment of patients with eating disorders. 3th ed. 2006. [cited 2009 Dez 22]. Available from: http://www.psychiatryonline.com

38. Chelune G, Ortega D, Linton J, Boustany M. Personality and cognitive findings among patients electing gastroplasty for morbid obesity. Int $J$ Eat Dis. 1986;5(4):701-12.

39. Boeka AG, Lokken K L. Neuropsychological performance of a clinical sample of extremely obese individuals. Arch Clin Neuropsychol. 2008;23(4):467-74. 